\begin{tabular}{|l|c|c|c|c|c|}
\hline $\begin{array}{l}\text { Nereis. Revista Iberoamericana } \\
\begin{array}{l}\text { Interdisciplinar de Métodos, } \\
\text { Modelización y Simulación }\end{array}\end{array}$ & 13 & $187-202$ & $\begin{array}{c}\text { Universidad Católica de } \\
\text { Valencia San Vicente Mártir }\end{array}$ & $\begin{array}{c}\text { Valencia } \\
\text { (España) }\end{array}$ & ISSN 1888-8550 \\
\hline
\end{tabular}

\title{
Clínica y sanidad de odontocetos y pinnípedos en cautividad y vida libre
}

\author{
Clinic and Health of Captive and Free-living Odontocetes and Pinnipeds
}

Fecha de recepción y aceptación: 7 de febrero de 2021 y 23 de junio de 2021

DOI: $10.46583 /$ nereis 2021.13.797

\author{
M. García Piqueras ${ }^{1}$ y J. Torres Gavilá ${ }^{*}$ \\ ${ }^{1}$ Instituto de Investigación en Medio Ambiente y Ciencia Marina (IMEDMAR). Universidad Católica de Valencia San Vicente Mártir. \\ *Correspondencia: Universidad Católica de Valencia San Vicente Mártir. Instituto de Investigación en Medio Ambiente y Ciencia \\ Marina (IMEDMAR). Calle Guillem de Castro, 9446001 Valencia. España. E-mail: javier.torres@ucv.es
}

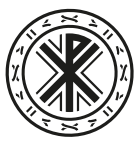

Universidad Católica de Valencia san Vicente Mártir

\section{RESUMEN}

Los océanos albergan el $71 \%$ de la superficie terrestre. Tal es su magnitud que, desde tiempos inmemoriales, el ser humano ha establecido multitud de vínculos con él y sus habitantes. Los mamíferos marinos, tales como odontocetos y pinnípedos, se han convertido en recursos biológicos fundamentales. Es por ello que el bienestar y la conservación de estos animales deben suponer una prioridad para el hombre, en su afán por seguir aprendiendo sobre el medio marino. La metodología empleada en la elaboración del presente artículo ha supuesto una revisión sistemática de la documentación científica más relevante acerca del tema de estudio.

Las enfermedades infecciosas son consideradas la principal causa de patología en estos animales. Entre los agentes víricos de mayor impacto destacan los géneros Poxvirus y Herpesvirus. El género bacteriano Brucella y los nematodos de la familia Anisakidae son conocidos por protagonizar las mayores epizootias en ambos grupos de mamíferos marinos.

Este trabajo pretende constituir la primera guía de aproximación acerca de las principales patologías infecciosas y aspectos clínicos de mayor impacto en odontocetos y pinnípedos, estableciendo una clara distinción entre aquellos que se encuentran en estado salvaje y los que viven en medios controlados.

PALABRAS CLAVE: mamíferos marinos, odontocetos, pinnípedos, enfermedades infecciosas.

\section{ABSTRACT}

The $71 \%$ of the Earth surface is covered with water. Such is its importance that from mankind beginning on, human being has been linked to it and its inhabitants. This way, marine mammals as odontocets and pinnipeds has become highly necessary biological resources for entertainment and environmental education. That is why the wellbeing and habitat of these species must be a priority for mankind as far as we keep on learning about sea life.

Overall scientific research has been methodologically revised in this report.

Infectious diseases are well known to be the main cause of disorder in these animals. The most viral agents in this kind of infections are the Poxvirus and Herpesvirus genera. The bacteria Brucella spp and the Anisakidae family of nematodes are known to be liable to bring about the major epizootic diseases in both marine mammals groups. 
This article seeks to set a first approach to main infectious pathologies and clinical aspects of odontocets and pinnipeds, drawing a clear distinction between wild and controlled living conditions.

KEYWORDS: marine mammals, odontocets, pinnipeds, infectious diseases.

\section{INTRODUCCIÓN}

El término mamifero marino hace referencia a ejemplares incluidos en los órdenes Carnivora y Sirenia, así como al infraorden Cetacea. Estos taxones se han visto sometidos a profundos cambios anatómicos y fisiológicos respecto a la clase Mammalia en general, desarrollando diversas adaptaciones al medio acuático (entre ellas la modificación de las extremidades en aletas, la adquisición de una espesa y aislante capa de tejido graso, diversas aptitudes natatorias y de inmersión, etc.). Los cetáceos son considerados el grupo mejor adaptado a la vida en el medio acuático. Un ejemplo sería el desarrollo de su aleta caudal como motor propulsor [1]. Se encuentran subdivididos en las superfamilias Odontoceti y Mysticeti. La principal diferencia entre ambos es la presencia de dientes o barbas. Los primeros emplean los dientes en la captura de presas, mientras que los misticetos han sustituido la dentición por láminas de queratina elásticas, que cuelgan del maxilar superior, las cuales les permiten filtrar el agua al tiempo que retienen pequeñas partículas de alimento [2].

El orden Carnivora incluye a los pinnípedos, los cuales a su vez se ramifican en tres familias principales: Phocidae, Otariidae y Odobenidae.

Junto con los cetáceos, constituyen los dos principales grupos de mamíferos marinos en cautividad y vida libre, amenazados clínicamente tanto por los patógenos de animales terrestres (mismo origen evolutivo), como por el propio medio marino, el cual se erige como refugio de una infinidad de patógenos que pueden causarles graves enfermedades, muchas de ellas especialmente devastadoras en poblaciones de especies amenazadas [3].

Daszak et al. [4] afirman que estos animales se encuentran expuestos a nuevas enfermedades a través de tres vías. La primera vía implica que las enfermedades emergentes entre la fauna salvaje aparezcan como resultado de la interacción entre estas y las especies domésticas (p. ej. la introducción del virus del moquillo canino (CDV) en una población de focas) [5]. La segunda vía de infección ocurre como consecuencia de los programas ex situ de repoblación con fines conservativos [4]. Dichas actividades se han convertido en un nexo que permite el movimiento de hospedadores y patógenos, facilitando la exposición de los mamíferos marinos a nuevas enfermedades. Finalmente, fenómenos naturales como El Niño, pueden intensificar la proliferación y/o transporte de patógenos. Esta tercera vía de transmisión tiene especial relevancia en los ecosistemas marinos de vida libre, siendo una de las principales causas del brote de nuevas enfermedades. 


\section{METODOLOGÍA}

Durante la búsqueda y selección bibliográfica para la elaboración del presente artículo, se encontró un total de 110 documentos. Dicha búsqueda se llevó a cabo ejecutando una serie de ecuaciones, donde el principal criterio de inclusión aplicado fue que la documentación tratara de manera directa o indirecta acerca de la clínica de ejemplares catalogados como "mamíferos marinos". A este primer criterio se sumó que la bibliografía recabada tratara sobre fauna salvaje y en cautividad. No fue seleccionado ningún artículo que superara los 30 años de publicación (primer criterio de exclusión).

Se revisó el texto completo de cada uno de los artículos. A continuación, se extrajeron las ideas principales y secundarias de cada uno de los artículos, con el propósito de confirmar que la información seleccionada estaba vinculada a nuestro objetivo (gráfico 1). No fue incluida ninguna publicación que contuviera información relativa a la familia Mustelidae, Ursidae, ni al orden Sirenia (segundo criterio de exclusión). El número de publicaciones seleccionadas ascendió a un total de 62 , siendo estas clasificadas por familias taxonómicas (gráfico 2).

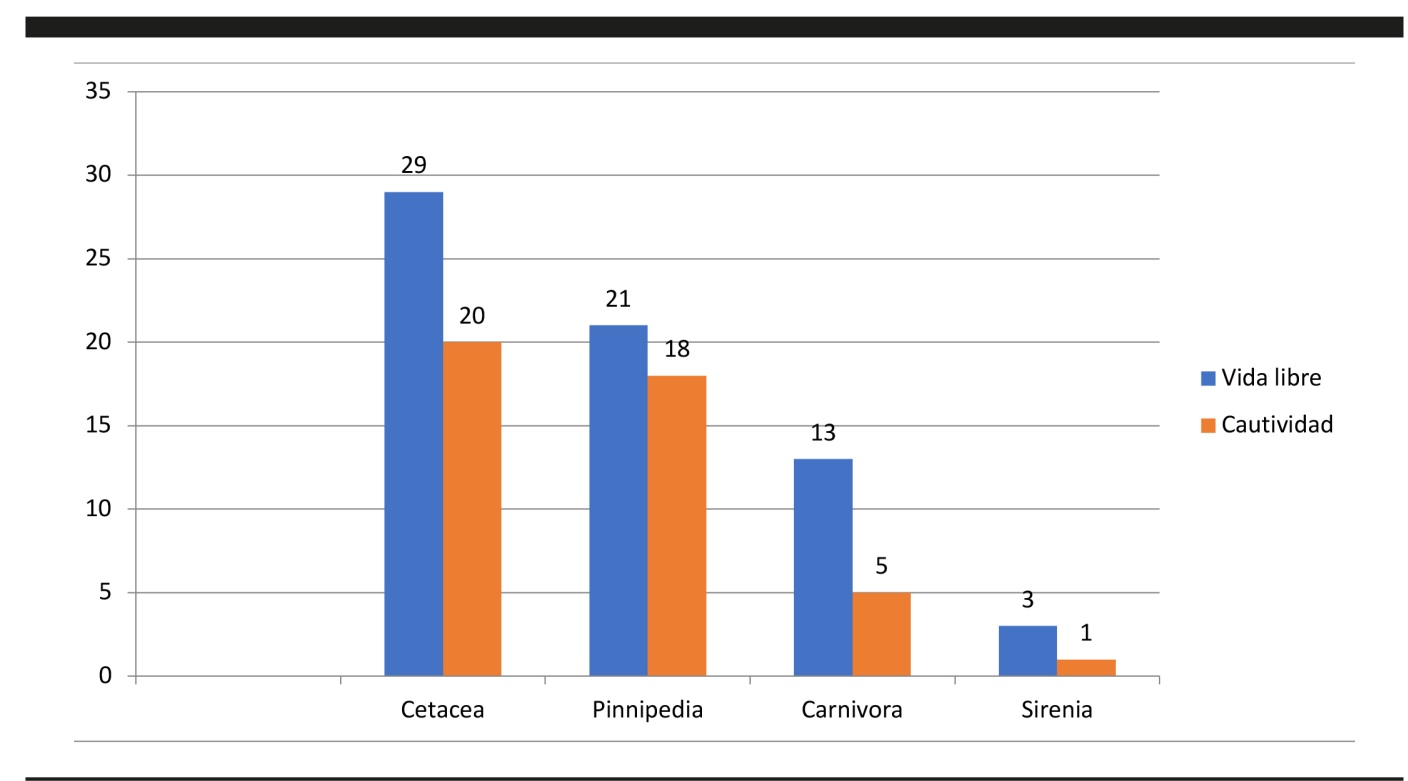

Gráfico 1. Clasificación de la información recabada en la búsqueda general. Fuente: elaboración propia. 


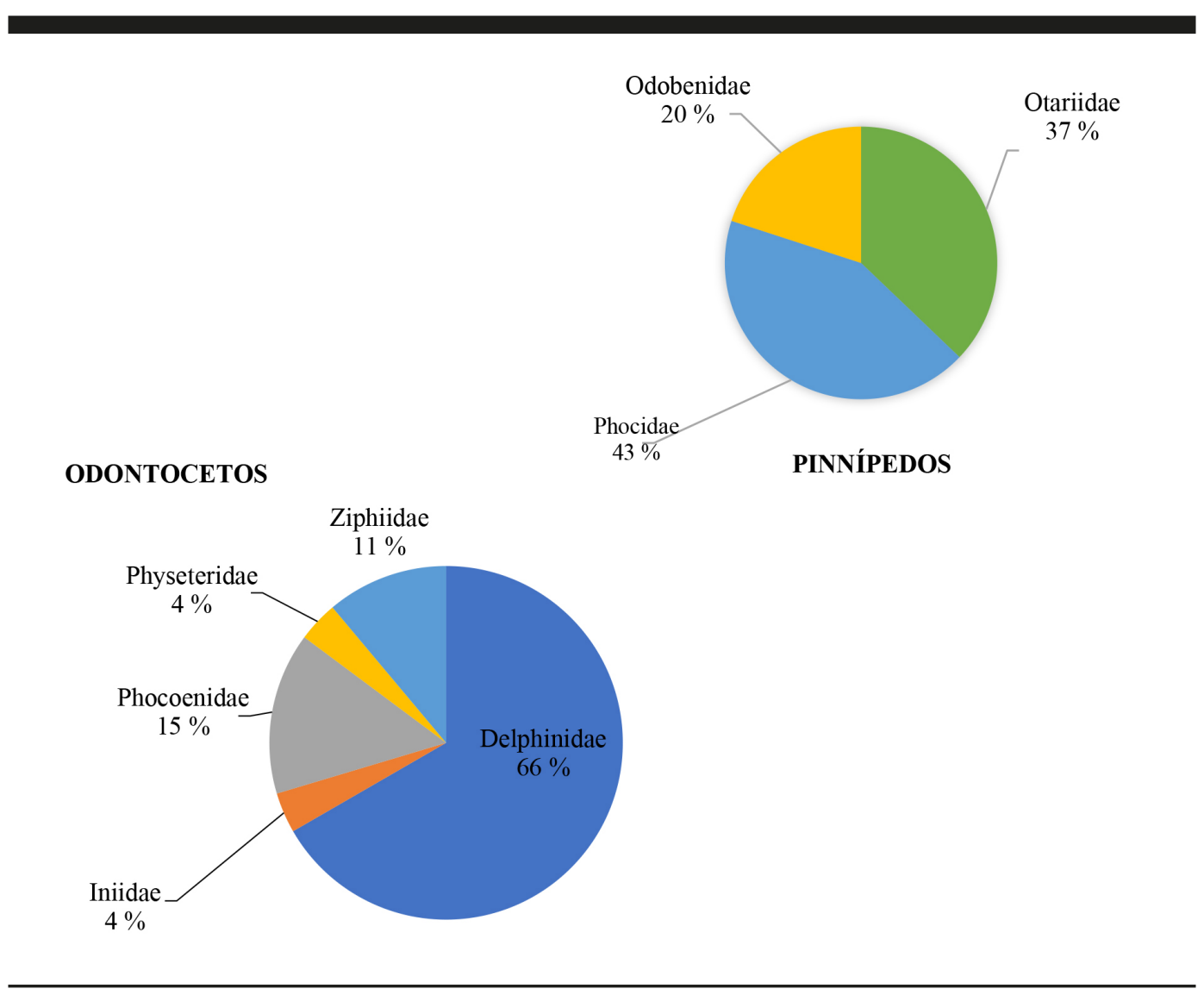

Gráfico 2. Clasificación de la documentación seleccionada. Fuente: elaboración propia.

\section{RESULTADOS Y DISCUSIÓN}

\section{Principales enfermedades infecciosas en odontocetos}

\section{Virus}

Tras su aparición en 1988, el Morbillivirus del cetáceo se subdividió en tres grupos diferenciados: Morbillivirus de las marsopas (PMV) [6], Morbillivirus de los delfines (DMV) [7] y el Morbillivirus de las ballenas piloto (PWMV) [8]. Se trata de un virus ARN de una sola hebra de sentido negativo, que contiene seis genes codificantes para ocho proteínas (dos no estructurales y seis estructurales organizadas en sentido 3'-5'). La base para sospechar de una infección por Morbillivirus son las lesiones macroscópicas identificadas en la necropsia (figura 1). Estas abarcan entre otras, lesiones pulmonares con ausencia de colapso total, múltiples focos de atelectasia, bronconeumonía exudativa en los lóbulos apicales y, edemas en ganglios linfáticos pulmonares. Macroscópicamente, es habitual encontrar signos compatibles con una encefalitis necrotizante multifocal, habiéndose reportado en ocasiones casos de estomatitis ulcerativa y gingivitis [9]. 


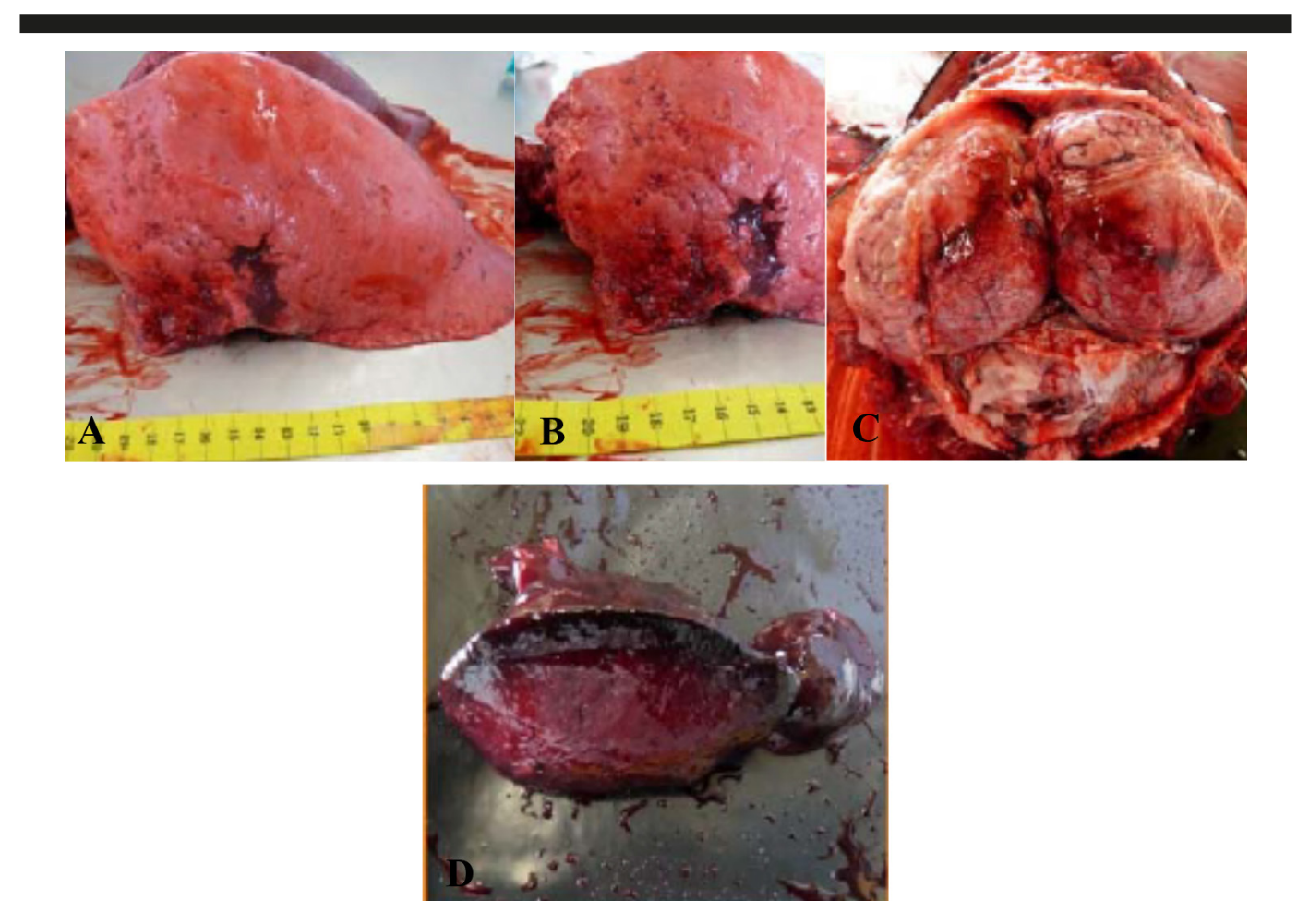

Fig. 1. Lesiones macroscópicas por CeMV. A y B) Atelectasia y consolidación del pulmón izquierdo; C) Hemorragia en encéfalo y meninges; D). Hiperplasia de ganglio linfático pulmonar reactivo [9]

La identificación se lleva a cabo tanto por técnicas inmunohistoquímicas como por detección de genoma mediante la reacción en cadena por polimerasa con transcripción reversa (RT-PCR convencional). La presencia de anticuerpos IgM en suero se confirma mediante la aplicación del test de neutralización viral (VN), test de neutralización por reducción en placa (PRNT) y el ELISA indirecto, el cual permite la detección de anticuerpos específicos frente al Morbillivirus. Hoy en día no existe ningún tratamiento descrito efectivo, dado que los ejemplares tratados con terapias de mantenimiento acaban pereciendo.

\section{Bacterias}

Los miembros del género Brucella son considerados unos de los agentes bacterianos de mayor impacto en la sanidad de los odontocetos, siendo Brucella ceti [10] y Brucella delphini [11] sus mayores representantes. La patogenia de la infección tiene como hallazgos clínicos relevantes la aparición de desórdenes reproductivos y patologías asociadas al sistema nervioso central (figura 2), pudiendo llegar a causar eventualmente la muerte del animal. 


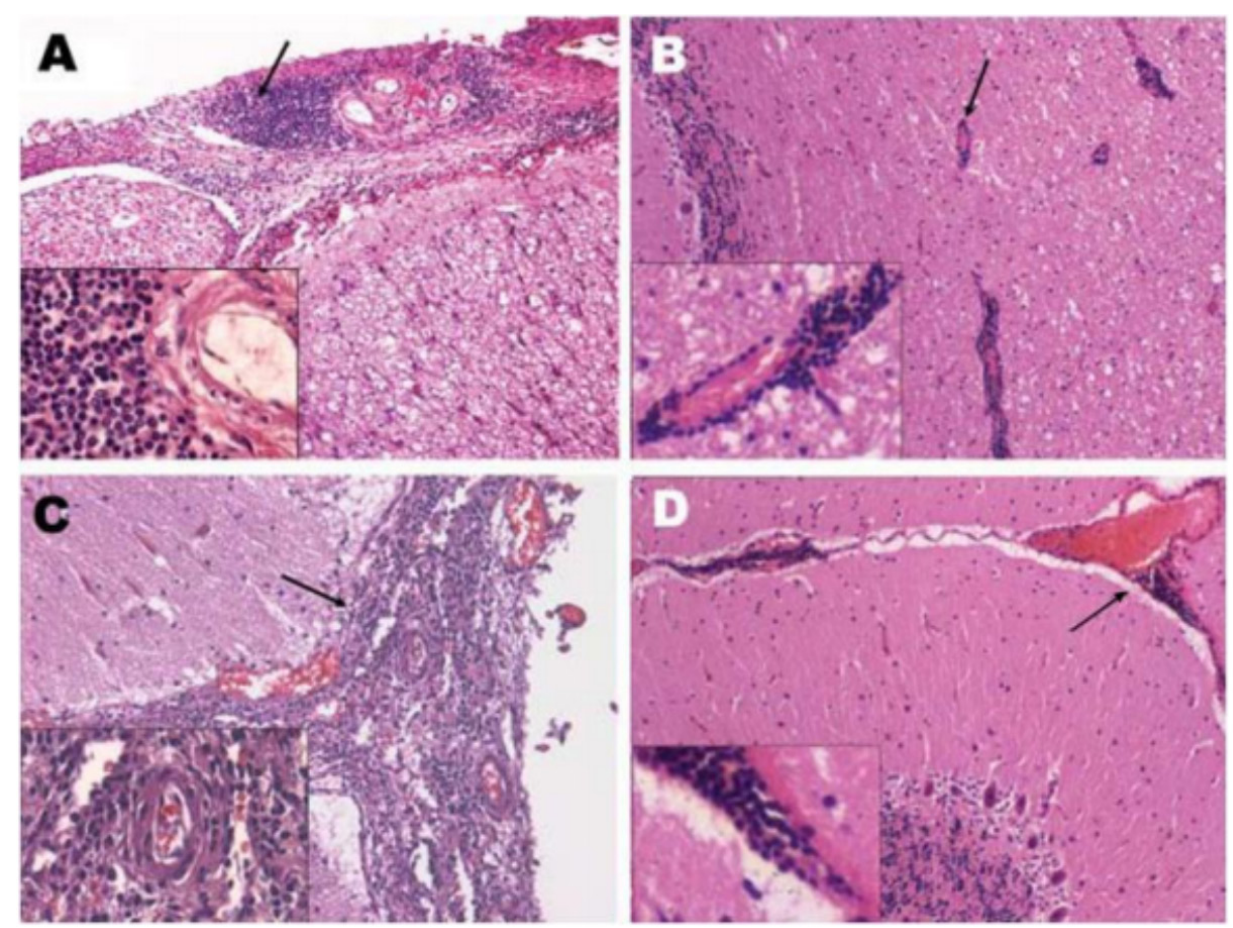

Fig. 2. Cortes histológicos de neurobrucelosis en Stenella coeruleoalba. A) Infiltrado mononuclear en las meninges, rodeando la médula espinal (flecha). HE 4X y 40X. B) Infiltrado mononuclear en los vasos cerebelares (flecha). HE 4X y 40X. C) Infiltrado mononuclear en las meninges alrededor del cerebro (flecha) HE 4X y 40X. D) Hiperemia e infiltrado mononuclear en las meninges rodeando al cerebelo (flecha). HE 4X y 40X [12]

Cabe citar que se trata de una bacteria que afecta a otros sistemas y órganos tales como el respiratorio o el hígado, no siendo difícil encontrar casos con neumonía intersticial no supurativa y hepatitis linfocítica periportal [13].

La batería de pruebas necesarias para alcanzar un diagnóstico fidedigno incluye análisis inmunohistoquímicos que permitan la detección de antígenos de Brucella. Posteriormente, se han incluido pruebas serológicas como diferentes test ELISA (cELISA, gELISA, iELISA), y PCR, así como aislamientos de líquido cefalorraquídeo (LCR) de los animales infectados [14].

Otros géneros de importancia en la clínica de odontocetos incluyen especies como Aeromonas hydrophila, Escherichia coli, Dermatophilus y Mycobacterium marinum, de especial relevancia en belugas (Delphinapterus leucas) [15]. Su principal órgano diana es la piel, donde ocasiona lesiones ulcerativas multicéntricas, dermatitis y paniculitis granulomatosa o lesiones nodulares en el caso de Pseudomonas aeruginosa, la cual afecta principalmente al delfín mular (Tursiops truncatus) [16].

\section{Parásitos}

Es acertado considerar a la gran mayoría de especies de odontocetos como hospedadores de una inmensa pluralidad de ectoparásitos marinos. Muchos de ellos utilizan su piel como sustrato para 
fijarse y filtrar alimento, como es el caso de los cirrípedos. Entre los principales géneros de cirrípedos se encuentran Amphibalanus, Balanus, Chelonibia, Conchoderma, Coronula y Xenobalanus [17]. En este último destaca la especie Xenobalanus globicipitis (figura 3), descrita como epibionte específico, localizado en el borde caudal de la aleta dorsal, aletas pectorales y aleta caudal de su hospedador [18].

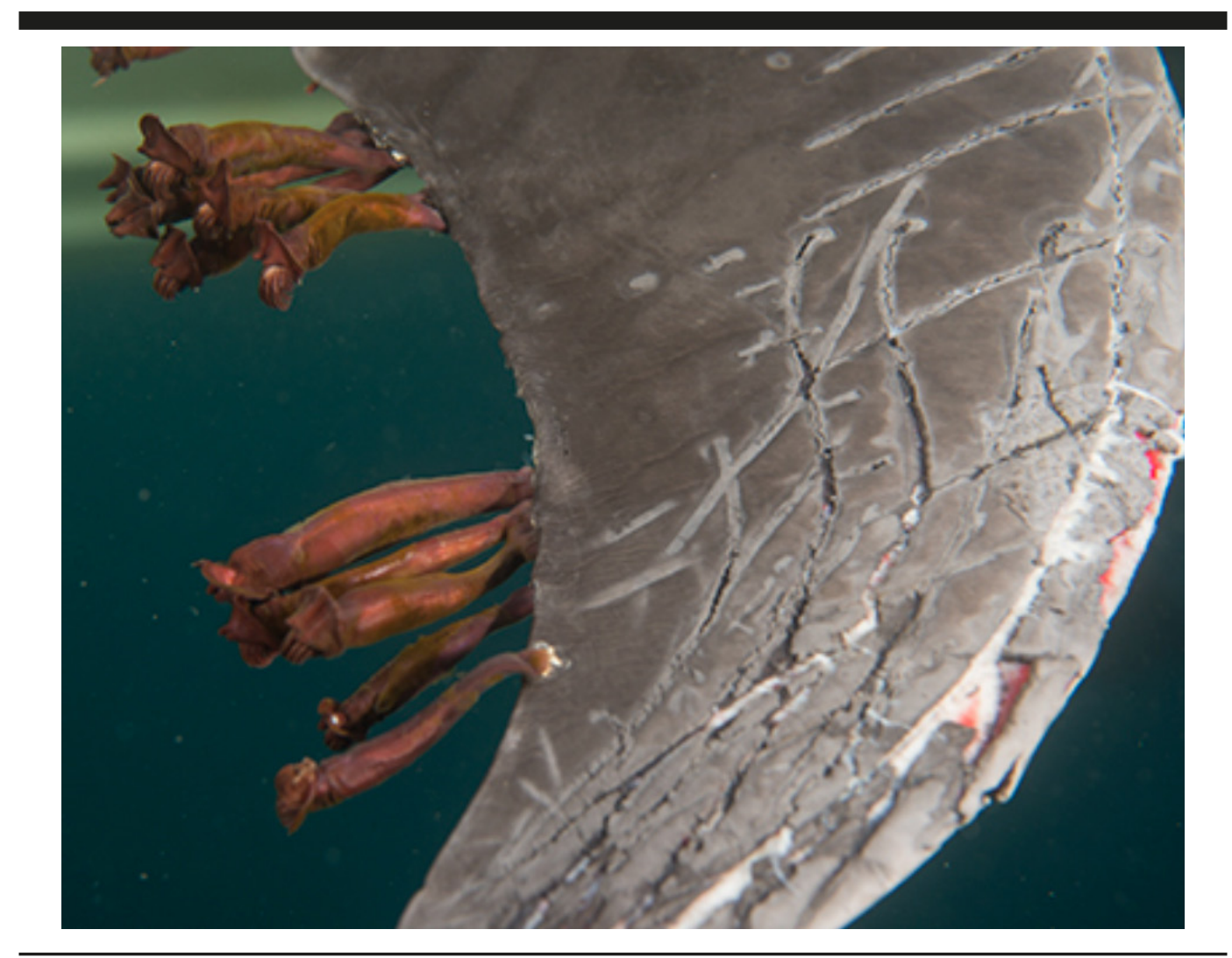

Fig. 3. Xenobalanus globicipitis en el borde de la aleta caudal de un delfín mular (Tursiops truncatus) [19]

Ciámidos y copépodos son otros habitantes habituales en odontocetos, principalmente en miembros de la familia Balaenopteridae. Entre los copépodos, destaca el género Penella, siendo P. balaenopteridae la especie de mayor repercusión clínica.

El diagnóstico histológico determina que las lesiones consisten en inflamación linfohistiocítica y granulomatosa acompañada de un infiltrado eosinofílico, hemorragias en dermis y tejido subcutáneo [20].

A nivel interno, Kyaroikeus cetarius es el protozoo ciliado de mayor renombre entre los endoparásitos que afectan al infraorden Cetacea. Ha sido identificado en delfines mulares en cautividad, delfines moteados (Stenella fontralis), delfines de Fraser (Lagenodelphis hosei) y orcas (Orcinus orca) [21]. La patogenia característica se manifiesta por medio de úlceras necróticas e inflamación dérmica y subcutánea subyacente.

El apicomplejo Toxoplasma gondii es el agente causal de una de las enfermedades parasitarias de mayor repercusión en mamíferos marinos, la toxoplasmosis. Afecta mayoritariamente al SNC, y se han descrito casos en calderones grises (Grampus griseus), delfines listados (Stenella 
coeruleoalba) y delfines mulares en cautividad (Tursiops truncatus) [22]. Clínicamente se manifiesta con la aparición de meningoencefalitis y coroiditis no supurativa con o sin desprendimiento del epitelio pigmentario asociado a la retina. Se han descrito casos con manguitos perivasculares linfoplasmocitarios e histiocíticos, astrogliosis, degeneración y necrosis neuronal con vacuolización, afección de las glándulas adrenales y cromatolisis (estadios avanzados de la infección). La patogenia también incluye la aparición de quistes intra y/o extracelulares con zoitos individuales [22] (figura 4).

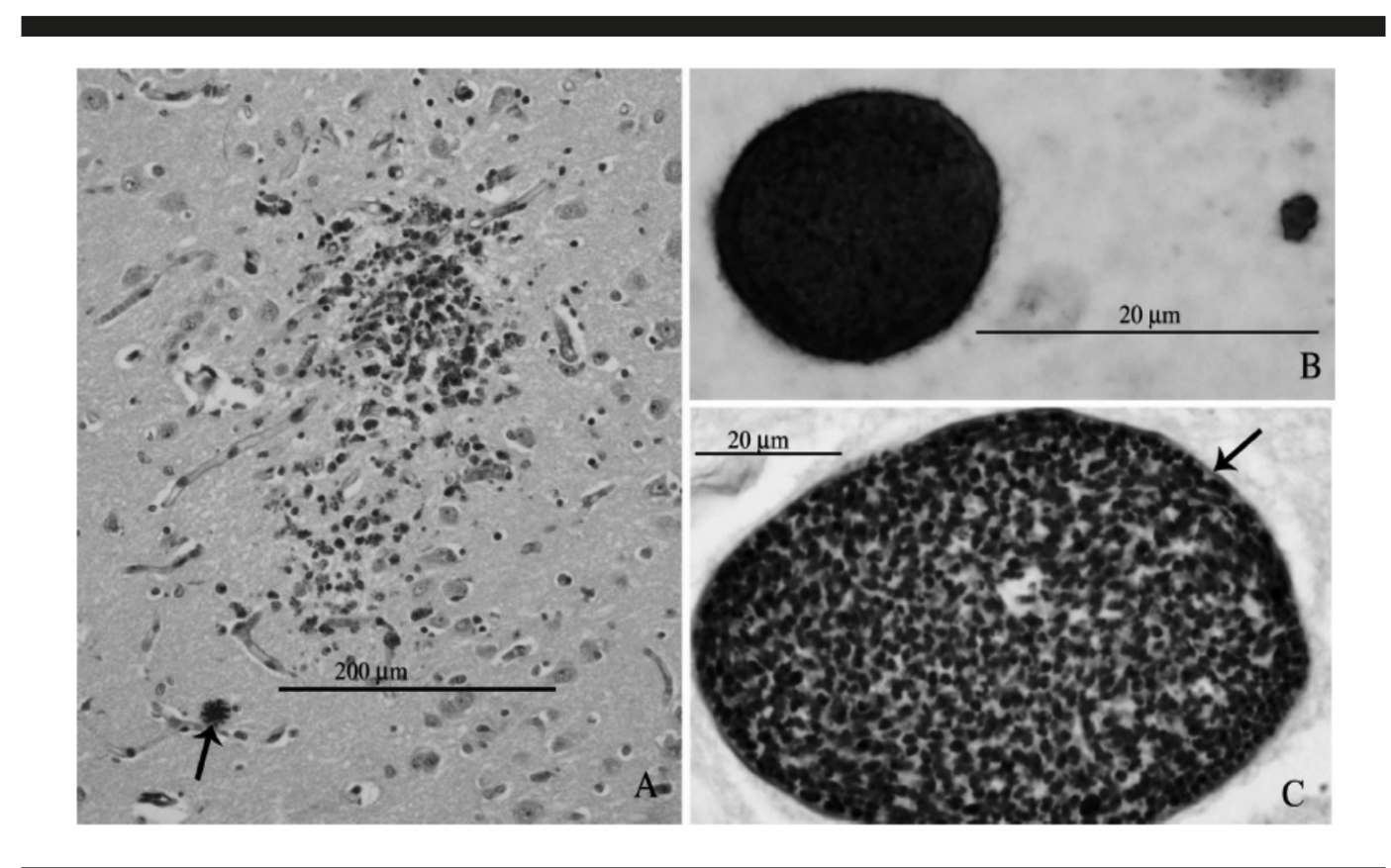

Fig. 4. Lesiones por Toxoplasma gondii en tejido cerebral de un delfín mular (Tursiops truncatus). A) Agregado de macrófagos y células de la microglía alrededor de un foco necrótico del neuropilo. La flecha indica la presencia de un quiste protozoario de pequeño tamaño. B) Dos grupos de T. gondii reaccionando frente anticuerpos policlonares. C) Quiste tisular teñido con tinción de PAS (la flecha señala la pared del quiste) [23]

El diagnóstico de la enfermedad incluye, entre otras, pruebas serológicas que permitan valorar la eficacia de los anticuerpos frente al parásito. También se han llevado a cabo bioensayos con muestras de tejido nervioso y musculoesquelético de animales infectados, así como análisis inmunohistoquímicos con tinciones convencionales (HE, PAS).

El tratamiento de la toxoplasmosis implica la adopción de unas rigurosas prácticas higiénicas y de seguridad alimentaria, añadidas a un control exhaustivo de la calidad del agua en todas las instalaciones, eliminando así cualquier posible vía de entrada y/o transmisión de la enfermedad.

Anisakis simplex., Contracaecum spp. y Pseudoterranova decipiens son tres de los principales géneros de nematodos encontrados frecuentemente en odontocetos. Localizados en la mucosa del estómago de sus hospedadores, una alta carga parasitaria puede provocar úlceras, gastritis y en casos excepcionales de no tratamiento, perforaciones. En estos casos, el diagnóstico se lleva a cabo por detección de huevos en heces (figura 5), o incluso de las formas adultas. Se recomienda tratamiento profiláctico rutinario con fenbendazol o ivermectina en mamíferos marinos en cautividad para prevenir la acumulación [22]. 


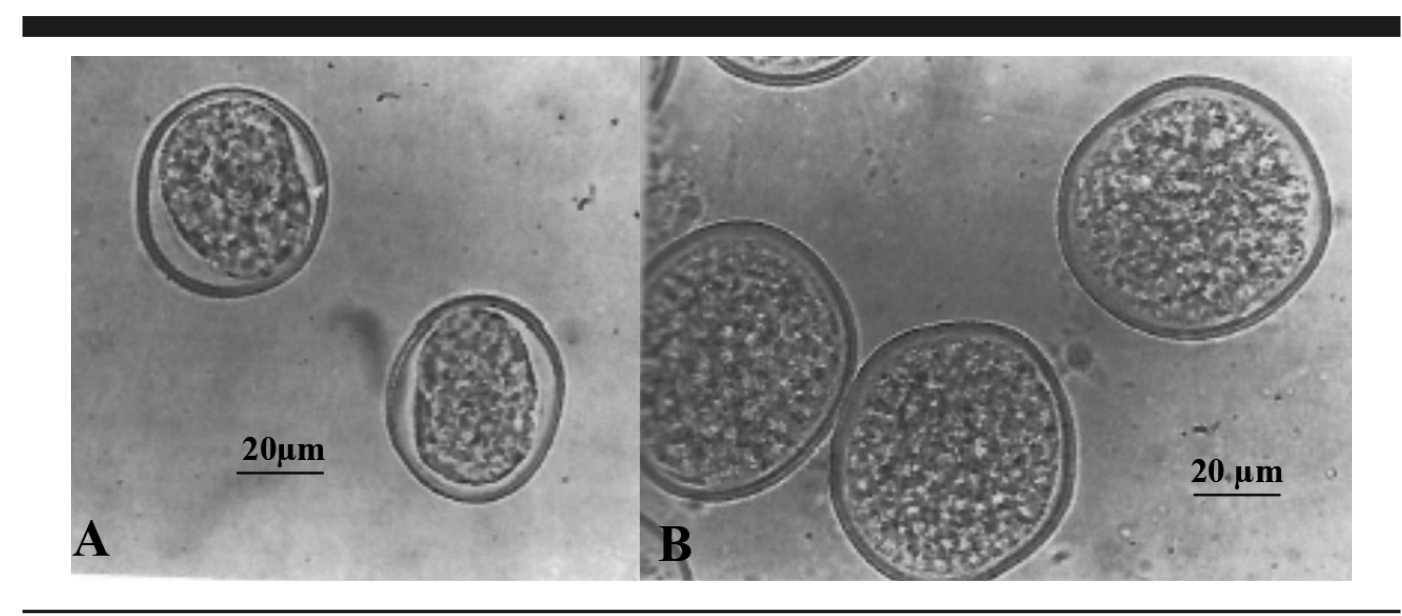

Fig. 5. A) Huevos de Anisakis simplex (x400). B) Huevos de Contracaecum spp. (x400) [2]

\section{Principales enfermedades infecciosas en pinnípedos}

\section{Virus}

Los géneros Poxvirus y Parapoxvirus (ambos de la familia Poxviridae) son considerados dos de los agentes víricos de mayor importancia patológica entre las poblaciones de pinnípedos de vida libre y en cautividad. En la última década, tuvo lugar una epidemia de Poxvirus que atacó gravemente a una población de leones marinos de la Patagonia (Otaria flavescens) en L'Oceanogràfic de Valencia (Departamento de Biología, pers. comm.). La transmisión de ambos virus tiene lugar por contacto directo con animales infectados y/o abscesos cutáneos que albergan partículas víricas. La patogenia de ambos virus se manifiesta esencialmente a través de lesiones cutáneas. En el caso de Poxvirus la distribución de estas puede variar, aunque normalmente sigue un patrón que abarca cabeza, cuello y aletas. La infección por Parapoxvirus se caracteriza sin embargo por la aparición de lesiones más específicas que afectan principalmente a la zona bucal (figura 6), incluyendo úlceras en mucosa y lengua, decoloración y aparición de verrugas [24].

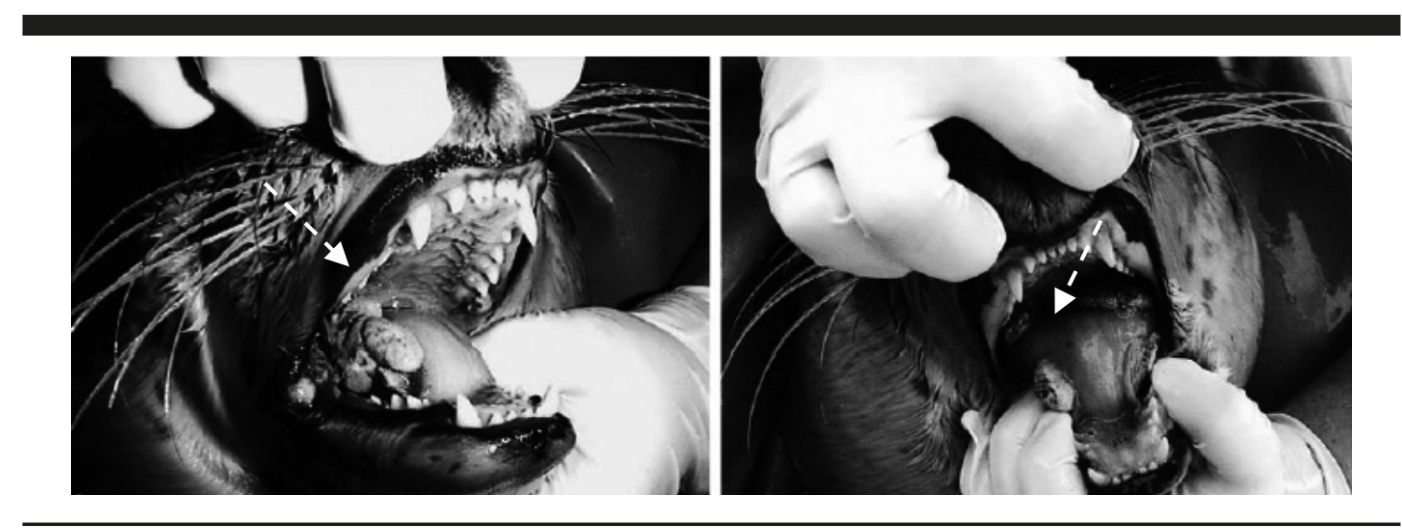

Fig. 6. Nódulos de conformación redonda-oval localizados en lengua y porción lateral de la boca (flechas discontinuas) de una foca común (Phoca vitullina) [24] 
El diagnóstico de la enfermedad se basa mayoritariamente en el análisis histológico de muestras obtenidas mediante biopsia. El resultado esperado es observar la presencia de eosinófilos y cuerpos de inclusión intracitoplasmáticos, con posterior confirmación por electromicroscopía. Al no causar enfermedad sistémica y ser autolimitante, por el momento no se ha descrito ningún tratamiento específico contra la enfermedad.

Continuando con los agentes virales de mayor relevancia, es necesario incluir a los miembros de la familia Herpesviridae (Herpesvirus de fócidos tipo 1 y 2, PhHV-1 y PhHV-2, respectivamente). El rango de edad de su hospedador es una de las principales características que diferencian a ambos subtipos (el PhHV-1 afecta con mayor frecuencia a pinnípedos jóvenes y neonatos) [2,25,26]. La infección por Herpesvirus tipo 1 (PhHV-1) se relaciona con sintomatología respiratoria (descarga nasal, inflamación de la mucosa oral), vómitos, diarreas y episodios de fiebre superior a $40{ }^{\circ} \mathrm{C}$ (el rango óptimo de temperatura en pinnípedos es de 36,5-37, ${ }^{\circ} \mathrm{C}$ ). Contrariamente, el Herpesvirus tipo 2 ha sido identificado como una enfermedad totalmente asintomática [25,26]. El diagnóstico de ambos subtipos implica el aislamiento del virus de los tejidos diana mediante biopsia (piel, vejiga urinaria, pulmón) o la toma de muestras de la descarga nasal mediante hisopo. El tratamiento recomendado en casos de infección sistémica se basa en la terapia de soporte. Esto implica el uso de Acyclovir vía oral (9-(2) hydroxyethoxymethyl guanina), un antivírico empleado en las infecciones por Herpesvirus en humanos [26].

\section{Bacterias}

El género Pasteurella es uno de los agentes bacterianos de mayor impacto en la superfamilia Pinnipedia, especialmente en individuos en cautividad. Su patogenia incluye lesiones tales como enteritis, hemorragias y peritonitis necrótica, diagnosticadas a partir de técnicas inmunohistoquímicas.

Actualmente la tetraciclina oral es el antibiótico profiláctico empleado en la mayoría de parques que alojan especies en cautividad (a una dosis de $250 \mathrm{mg} / \mathrm{animal} \mathrm{BID).}$

La leptospirosis es una enfermedad zoonótica bacteriana, conocida en pinnípedos a partir de la gran epidemia de leones marinos californianos (Zalophus californianus) a lo largo de las costas de Oregón en 1970. La epizootia afectó a cientos de animales, al tiempo que multiplicó por cuatro el número de leones marinos varados. La transmisión del patógeno creó cierta controversia entre los investigadores. Estudios serológicos en lobos marinos árticos (Callorhinus ursinus) afirmaban que la exposición a L. pomona se producía en el mar. Sin embargo, el aislamiento del patógeno a partir del tejido placentario en leones marinos californianos de la isla de San Miguel indicó que la exposición en el ambiente rocoso también podría haber actuado como reservorio de la enfermedad [27,28]. Los signos clínicos descritos incluyen depresión, polidipsia, episodios de fiebre, anorexia y ocasionalmente ictericia, vómitos y temblores musculares (figura 7). Algunos autores afirman que la leptospirosis en pinnípedos implica leucocitosis y azotemia (aumento de la creatinina y el nitrógeno ureico en sangre o BUN). Los individuos más jóvenes presentaban hemoabdomen, hemorragias internas en hígado y riñón [29]. 


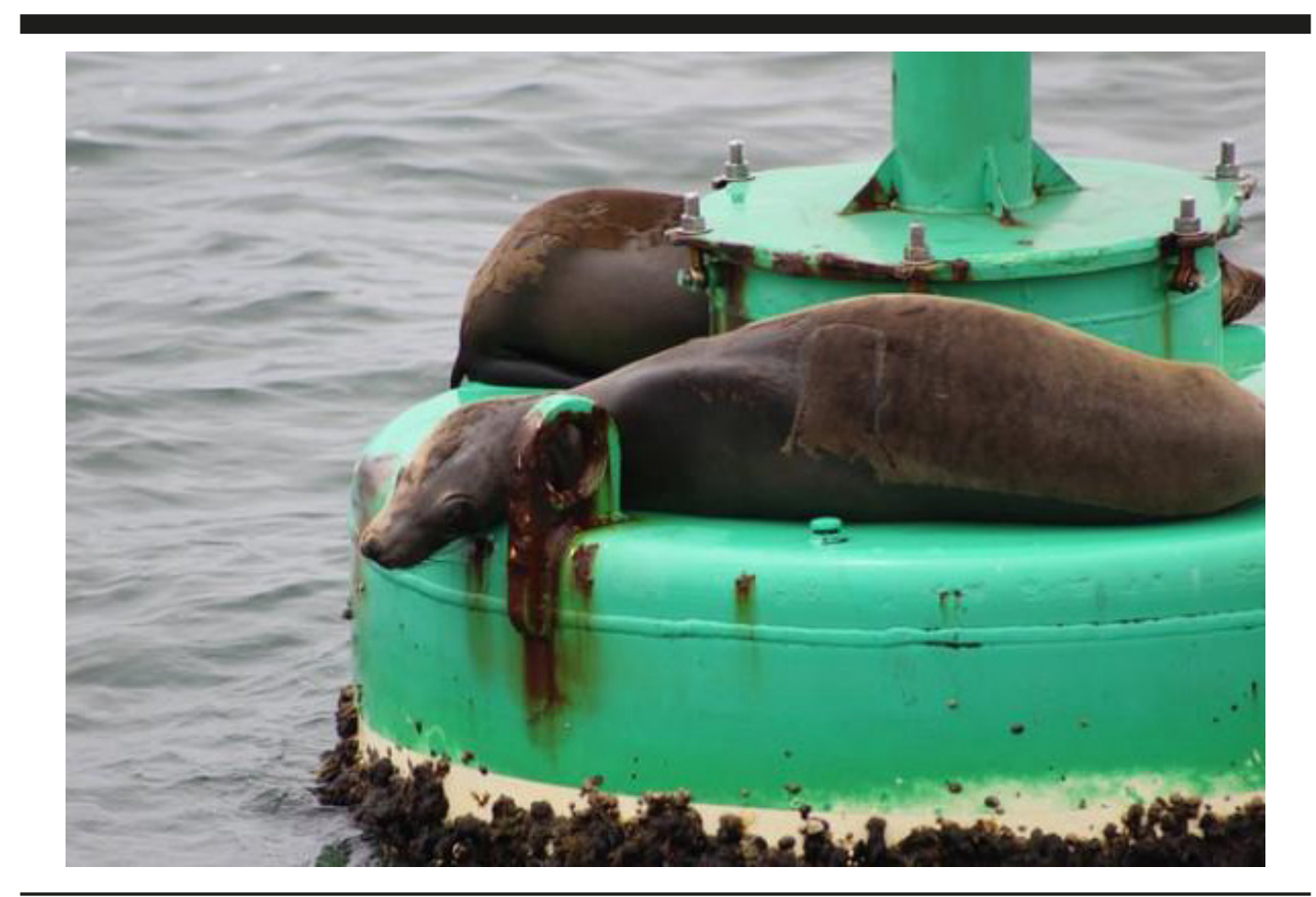

Fig. 7. León marino californiano (Zalophus californianus) en la costa de Oregón (2014). Pueden observarse signos de anorexia, depresión y estado apático como consecuencia de la infección por Leptospira.

Fuente: Petetzak.com

Los análisis histopatológicos mostraron nefritis intersticial difusa y glomerulonefritis. También se observó un gran número de espiroquetas en diferentes tramos renales.

Entre los tratamientos más efectivos contra la leptospirosis se encuentra el uso de estreptomicina combinado con complejo vitamínico B. También han resultado exitosos otros tratamientos como la Penicilina $\mathrm{G}$ potasio vía oral (44 U/kg dos veces al día) durante 10-14 días. Stamper et al. [29] trataron una foca común en cautividad con tetraciclina, fijadores de fósforo y suplementación oral de electrolitos con resultados satisfactorios.

\section{Parásitos}

Eimeria phocae es probablemente el coccidio por excelencia entre los pinnípedos, especialmente en cautividad. Se trata de una enfermedad con sintomatología inespecífica como letargia, heces sanguinolentas y convulsiones intermitentes alternadas con espasmos musculares que preceden, en muchos casos, al fallecimiento del animal. Al tratarse de una enfermedad sistémica, las técnicas diagnósticas de elección requieren la toma de biopsias en múltiples órganos (tejido cerebral, médula espinal, hígado, riñón, bazo, tráquea, pulmón, glándulas adrenales, páncreas, estómago, intestino delgado y grueso, piel, entre otras), a fin de proceder a un análisis histológico con electromicroscopía. Los hallazgos histopatológicos descritos incluyen inflamación de la pared intestinal en el último tercio del yeyuno e íleon, presencia de sangre de color oscuro, e inflamación del yeyuno y duodeno (figura 8). 


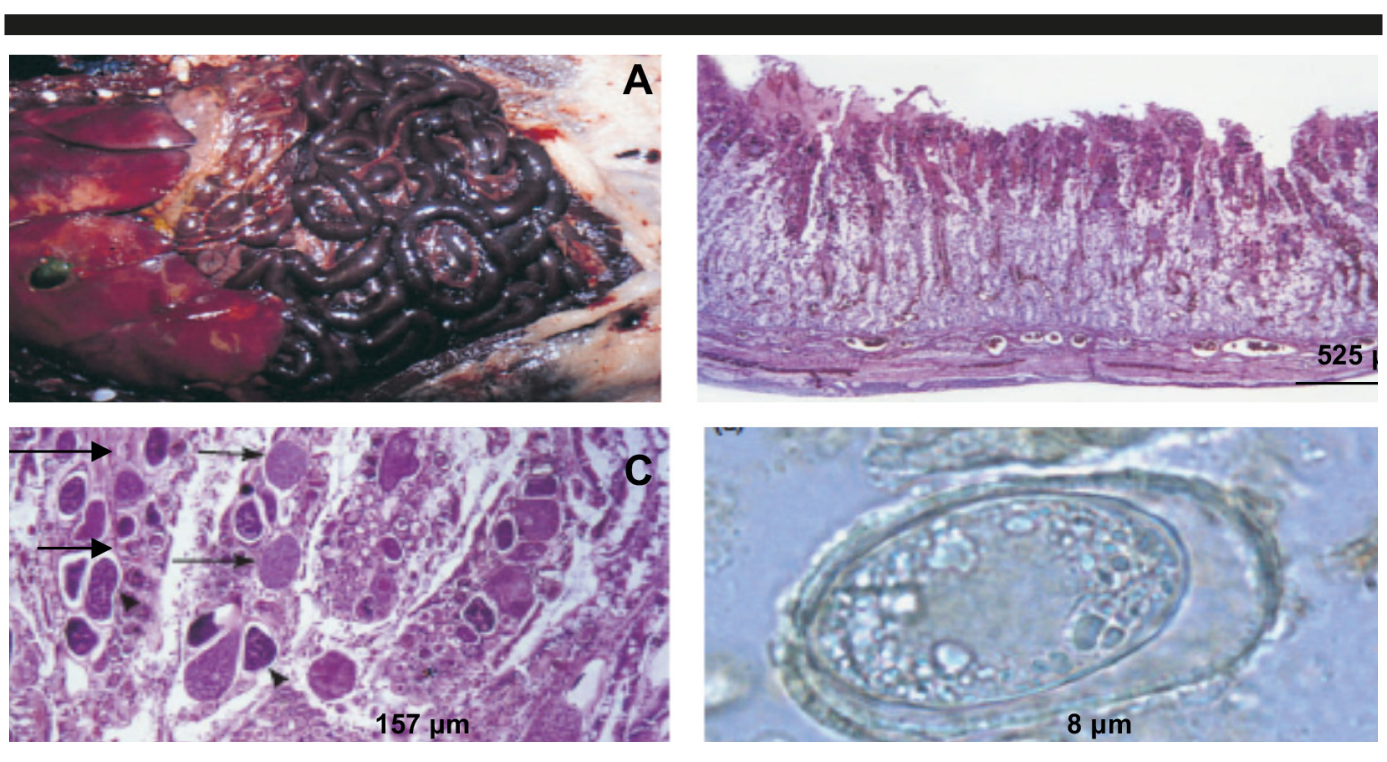

Fig. 8. A) Hemorragia necrótica y enterocolitis por infección de E. phocae en foca común (Phoca vitullina). B) Colon hemorrágico con zonas necróticas, donde puede observarse la presencia de ooquistes en la lámina propia de la mucosa (flecha). HE.

Bar $=525 \mu \mathrm{m}$. C) Sección del duodeno con signos de hemorragia y necrosis. Las flechas señalan la elevada concentración de gamontes de $E$. phocae en la lámina propia.

HE. $B a r=157 \mu \mathrm{m}$. D) Ooquiste de E. phocae en la mucosa intestinal. Bar $=8 \mu \mathrm{m}$ [30]

Como tratamiento médico, se recomienda el uso de sulfonamidas que interfieran en el metabolismo del coccidio y antibióticos de amplio espectro en caso de que se sospeche de una infección bacteriana secundaria en el intestino [30].

Dentro de los parásitos trematodos de mayor renombre en la superfamilia Pinnipedia, cabe citar la presencia de Galactosomum stelleri, localizado en el intestino delgado de leones marinos de Steller (Eumetopias jobatus) y leones marinos californianos (Zalophus californianus). Otros trematodos de importancia incluyen los géneros Rossicotrema, Phagicola y Cryptocotyle. Este último ha sido descrito en focas del mar Caspio [31]. Ogmogaster spp ha sido identificado en el tejido intestinal, causante de graves epizootias en leones marinos australianos (Neophoca cinerea) [2].

Los ectoparásitos más frecuentes en pinnípedos incluyen miembros del orden Phthiraptera y Mesostigmata, con especial relevancia de los géneros Anoplura, Demodex y Sarcoptes, respectivamente.

También es frecuente encontrar ejemplares de Antarctophthirus microchir en la piel de lobos marinos californianos (Zalophus californianus), con predisposición por la región perigenital (figura 9A) [32].

Orthohalarachne y Halarachne (figura 9B) son dos géneros de la familia Halarachnidae, conocidos por ser parásitos obligados de las vías respiratorias superiores e inferiores de pinnípedos. Las lesiones asociadas con la infestación de estos ácaros implican erosión e inflamación de los cornetes nasales y nasofaringe [33]. 


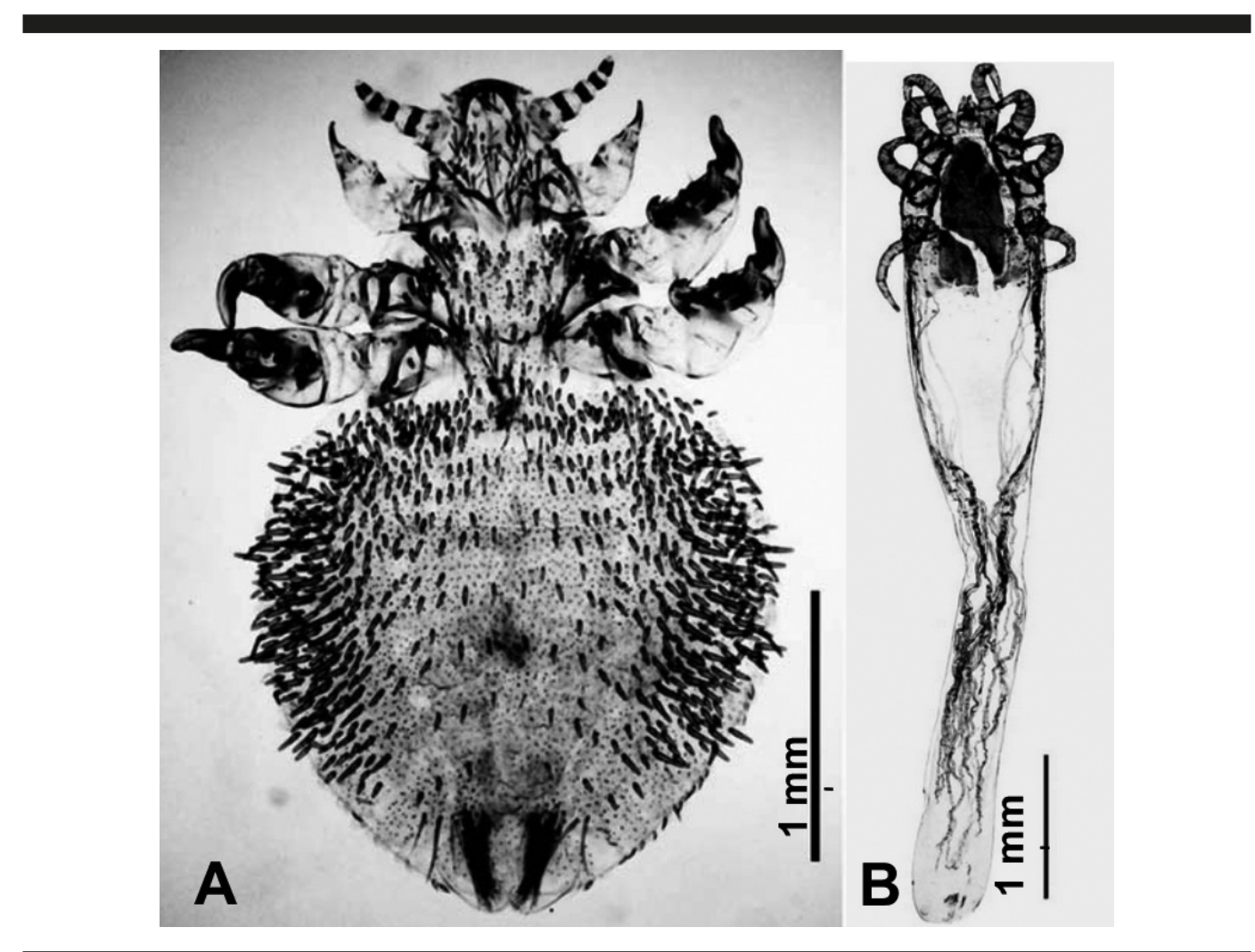

Fig. 9. A) Vista ventral de un ejemplar adulto de Antarctophthirus microchir (escala: $1.0 \mathrm{~mm}$ ). B) Vista ventral de un ejemplar adulto hembra de Orthohalarachne attenuata (escala $1.0 \mathrm{~mm}$ ) [33]

\section{CONCLUSIÓN}

Las enfermedades infecciosas que afectan a odontocetos y pinnípedos se desencadenan a partir de tres grupos de patógenos principales: virus, bacterias y parásitos. Asimismo, la especificidad de cada agente patógeno varía sustancialmente según el hábitat de su hospedador, no siendo los mismos aquellos que afectan a especies en cautividad y en estado salvaje. La sintomatología de cada patología varía según el agente etiológico en cuestión, siendo los síntomas y signos clínicos más frecuentes las lesiones cutáneas, estado febril e inmunosupresión para el caso de agentes víricos, anorexia, linfadenomegalia y lesiones ulcerativas en patógenos bacterianos, y afección del sistema enterohepático, tejido nervioso y músculo esquelético además de alopecia e irritación cutánea para el caso de formas parásitas.

La aproximación diagnóstica de cada enfermedad depende en gran medida del tipo de lesión, tejido afectado, agente etiológico y ciclo biológico de este. No obstante, podemos afirmar que en la detección de agentes infecciosos, el análisis histopatológico basado en técnicas inmunohistoquímicas es considerado la técnica de referencia o gold standard. 
Los tratamientos clínicos planteados contemplan rigurosas prácticas de higiene y antibioterapia de amplio espectro, haciendo hincapié en la referente a los microorganismos Gram negativos, y el uso de antiparasitarios pertenecientes al grupo de los benzimidazoles o las ivermectinas, entre otros.

Sirva este artículo como guía de referencia para una primera consulta clínica de las patologías más comunes que afectan a odontocetos y pinnípedos, así como elemento de apoyo en su diagnóstico y tratamiento.

\section{REFERENCIAS BIBLIOGRÁFICAS}

[1] Reeves RR, Stewart BS, Clapham PJ, Powell JA. Guide to Marine Mammals of the World. Barcelona: Omega; 2005.

[2] Dailey M. Parasitic Diseases. En: Dierauf LA, Gulland MD, editores. CRC Handbook of Marine Mammal Medicine. Vol 30. 2. ${ }^{a}$ ed. Florida: Aquatic Mammals; 2004, pp. 357-374.

[3] Harwood J, Hall A. Mass mortality in marine mammals: its implications for population dynamics and genetics. Trends Ecol Evol. 1990;5(8):254-7.

[4] Daszak P, Cunningham AA, Hyatt AD. Emerging infectious diseases of wildlife-threats to biodiversity and human health. Science. 2000;287(5459):443-449.

[5] Ross P, Visser I, Broeders H, van de Bildt M, Bowen W, Osterhaus A. Antibodies to phocine distemper virus in Canadian seals. Vet Rec. 1992;130(23):514-6.

[6] Kennedy S, Kuiken T, Jepson PD, Deaville R, Forsyth M, Barret T, et al. Mass Die-Off of Caspian Seals caused by Canine Distemper Virus. J Emerg Infect Dis. 2000;6(6): 637-639.

[7] Osterhaus AD, Groen J, Spijkers HE, Broeders HW, UytdeHaag FG, de Vries P, et al. Mass mortality in seals caused by a newly discovered virus-like Morbillivirus. Vet Microbiol. 1990;23(14):343-50.

[8] Lipscomb TP, Mense MG, Habecker PL, Taubenberger JK, Schoelkopf R. Morbilliviral dermatitis in seals. Vet Pathol. 2001;38(6):724-726.

[9] Rubio-Guerri C, Sánchez-Vizcaíno JM (dir). Detección, prevalencia y epidemiología molecular de virus en cetáceos del Mediterráneo [tesis doctoral]. Madrid: Universidad Complutense de Madrid; 2015 [consultado: 11 enero 2021].

[10] Dagleish MP, Barley J, Finlayso J, Reid RJ, Foster G. Brucella ceti associated pathology in the testicle of a harbour porpoise (Phocoena phocoena). J Comp Pathol. 2008;139(1):54-59.

[11] Bourg G, O'Callaghan D, Boschiroli ML. The genomic structure of Brucella strains isolated from marine mammals gives clues to evolutionary history within the genus. Vet Microbiol. 2007; 125:375-380.

[12] Hernández Mora MG, Moreno Robles E (dir). Diagnóstico de infecciones causadas por Brucella ceti en cetáceos [tesis doctoral]. Río Facio: Universidad de Costa Rica; 2011 [consultado: 28 noviembre 2020].

[13] Guzmán-Verri C, González-Barrientos R, Hernández-Mora G, Morales J-A, Baquero-Calvo E, Chaves-Olarte E, et al. Brucella ceti and Brucellosis in Cetaceans. Front Cell Infect Microbiol. 2012;2:1-22. 
[14] Foster G, Jahans KL, Reid RJ, Ross HM. Isolation of Brucella species from cetaceans, seals and an otter. Vet Rec. 1996;138(24):583-6.

[15] Thompson LA, Romano TA. Beluga (Delphinapterus leucas) granulocytes and monocytes display variable responses to in vitro pressure exposures. Front Physiol. 2015;6:1-14.

[16] Flowers, DJ. Human infection due to Mycobacterium marinum after a dolphin bite. J Clin Pathol.1970;23(6):475-7.

[17] Fertl D, Newman WA. Barnacles. En: Perrin WA, Würsig B, Thewissen JG, editores. Encyclopedia of Marine Mammals. 2. a ed. London: Academic Press; 2009, pp. 89-91.

[18] Whitehead TO, Rollinson DP, Reisinger RR. Pseudostalked barnacles Xenobalanus globicipitis attached to killer whales Orcinus orca in South African waters. Mar Biodiv. 2014;1(4).

[19] Carrillo JM, Overstreet RM, Raga JA, Aznar FJ. Living on the Edge: Settlement Patters by the Symbiotic Barnacle Xenobalanus globicipitis on small cetaceans. PLoS One. 2015;10(6):1-15.

[20] Danyer E, Tonay AM, Aytemiz I, Dede A, Yildirim F, Gurel A. First report of infestation by a parasitic copepod (Pennella balaenopterae) in a harbour porpoise (Phocoena phocoena) from the Aegean Sea: a case report. Vet Med. 2014;59(8):403-407.

[21] Choi YK, Kang MS, Sohn HR, Kim DY. Disseminated ciliated protozoan infection in a Pacific dolphin (Tursiops gilli). Vet Rec. 2003;153(23):714-5.

[22] Dubey JP, Mergl J, Gehring E, Sundar N, Velmurugan GV, Kwok OCH, et al. Toxoplasmosis in Captive Dolphins (Tursiops truncatus) and Walrus (Odobenus rosmarus). J Parasitol. 2009;95(1):82-5.

[23] Díaz-Delgado J, Fernández A (dir). Patología y causa de la muerte de los cetáceos varados en las Islas Canarias (2006-2012) [tesis doctoral]. Las Palmas de Gran Canaria: Universidad de Las Palmas de Gran Canaria; 2015 [consultado: 13 octubre 2020].

[24] Müller G, Gröters S, Siebert U, Rosenberg T, Driver J, Köning M, et al. Parapoxvirus infection in Harbour Seals (Phoca vitulina) from the German North Sea. Vet Pathol. 2003;40:445-454.

[25] Trupkiewicz JG, Gulland FM, Lowenstine LJ. Congenital defects in northern elephant seals stranded along the central california coast. J Wild Dis. 1997;33(2):220-225.

[26] Gulland FMD, Lowenstine LJ, Lapointe JM, Spraker T, King DP. Herpesvirus Infection in Stranded Pacific Harbor Seals of Coastal California. J Wildl Dis. 1997;33(3):450-8.

[27] Kennedy-Stoskopf S. Viral Diseases. En: Dierauf LA, Gulland MD, editores. CRC Handbook of Marine Mammal Medicine. Vol. 30. 2. ${ }^{a}$ ed. Florida: Aquatic Mammals; 2004, pp. 285-303.

[28] Dierauf LA, Vandenbroek DJ, Roletto J, Koski M, Amaya L, Gage LJ. An epizootic of leptospirosis in California sea lions. J Am Vet Med Assoc. 1985;187(11):1145-1148.

[29] Stamper MA, Gulland FM, Spraker T. Leptospirosis in rehabilitated Pacific harbor seals from California. J Wildl Dis. 1998;34:407-410.

[30] Van Bolhuis GH, Philippa JD, Gajadhar AA, Osterhaus AD, Kuiken T. Fatal enterocolitis in harbour seals (Phoca vitulina) caused by infection with Eimeria phocae. Vet Rec. 2007;160(9):297300.

[31] Van Bolhuis GH, Philippa JD, Gajadhar AA, Osterhaus AD, Kuiken T. Fatal enterocolitis in harbour seals (Phoca vitulina) caused by infection with Eimeria phocae. Vet Rec. 2007;160(9):297300 . 
[32] Leonardi MS, Crespo EA, Raga JA, Fernández M. Redescription of Antarctophthirus microchir (Anoplura: Echinophthiriidae) from the South American Sea Lion, Otaria flavescens, from Patagonia, Argentina. J Parasitol. 2009;95(5):1086-92.

[33] Gomez- Puerta LA, Gonzales-Viera O. Ectoparásitos del lobo marino sudamericano (Otaria flavescens) de la costa peruana. Rev Peru Biol. 2015;22(2):259-262.

[34] Ebmeri D, Navarrete-Talloni MJ, Muñoz P, Hermosilla C. Antarctophthirus microchir infestation in synanthropic South American sea lion (Otaria flavescens) males diagnosed by a novel non-invasive method. Parasitol Res. 2019;118(5):1351-1361. 